ARTICLE

https://doi.org/10.1038/s41467-019-10542-0

\title{
Probing the active fraction of soil microbiomes using BONCAT-FACS
}

\author{
Estelle Couradeau (10 1, Joelle Sasse (10 1, Danielle Goudeau (10 2, Nandita Nath², Terry C. Hazen (1) ${ }^{3}$, Ben P. Bowen², \\ Romy Chakraborty (1) ${ }^{4}$, Rex R. Malmstrom² \& Trent R. Northen (i) ${ }^{1,2}$
}

The ability to link soil microbial diversity to soil processes requires technologies that differentiate active microbes from extracellular DNA and dormant cells. Here, we use BONCAT (bioorthogonal non-canonical amino acid tagging) to measure translationally active cells in soils. We compare the active population of two soil depths from Oak Ridge (Tennessee, USA) and find that a maximum of $25-70 \%$ of the extractable cells are active. Analysis of $16 \mathrm{~S}$ rRNA sequences from BONCAT-positive cells recovered by fluorescence-activated cell sorting (FACS) reveals that the phylogenetic composition of the active fraction is distinct from the total population of extractable cells. Some members of the community are found to be active at both depths independently of their abundance rank, suggesting that the incubation conditions favor the activity of similar organisms. We conclude that BONCAT-FACS is effective for interrogating the active fraction of soil microbiomes in situ and provides a new approach for uncovering the links between soil processes and specific microbial groups.

\footnotetext{
${ }^{1}$ Environmental Genomics and Systems Biology, Lawrence Berkeley National Laboratory, Berkeley, CA, USA. ${ }^{2}$ Joint Genome Institute, Department of Energy, Walnut Creek, CA, USA. ${ }^{3}$ University of Tennessee, Oak Ridge National Laboratory, Oak Ridge, TN, USA. ${ }^{4}$ Earth Science and Environmental Sciences, Lawrence Berkeley National Laboratory, Berkeley, CA, USA. Correspondence and requests for materials should be addressed to T.R.N. (email: TRNorthen@lbl.gov)
} 
S oil communities are composed of thousands of species and reach densities of millions to billions of cells within each gram of material ${ }^{1,2}$. Together, they perform key nutrient cycling functions and, as a collective, are dominant contributors to Earth's biogeochemical cycles ${ }^{3}$. Next generation sequencing enables a detailed examination of the microbial taxa inhabiting soils $^{4}$, and allows for comparisons across a large sets of samples with the aim of pinpointing the drivers of the microbial diversity $3,5,6$. Such comparative studies reveal patterns of diversity that emerge in soils, especially in terms of correlation with edaphic factors, such as $\mathrm{pH}^{7}$, soil texture ${ }^{8}$ or moisture content ${ }^{9}$, or biological factors, such as species-species interaction, life strategy $^{10}$ or rank abundance ${ }^{6}$. Recent reports have suggested that a large fraction, possibly up to $\sim 40 \%$, of the microbial diversity retrieved from soils by molecular methods might come from dead cells or extracellular $\mathrm{DNA}^{11}$, and that up to $>95 \%$ of cells may be dormant at a given point in time depending on the studies ${ }^{12-14}$. Thus, it is challenging to extrapolate links between soil processes and community composition using traditional screening methods $^{15}$. Complementary technologies are needed to distinguish between active cells driving soil processes and the inactive cells that do not ${ }^{15}$.

Active microorganisms have been identified previously using stable isotope probing (SIP) or bromodeoxyuridine (BrdU) labeling. SIP encompasses a series of methods that involve the incorporation of heavy isotopes into newly synthetized DNA and its separation on a density gradient ${ }^{16}$. SIP using labeled ${ }^{13} \mathrm{C}$ compounds has shed light onto how the soil microbiome metabolizes certain molecules of interest such as cellulose ${ }^{17}$. Although SIP has been successfully implemented in soils, it remains technically challenging, labor and cost intensive ${ }^{18}$, and can be confounded by cross-feeding and label dilution effects ${ }^{19}$. BrdU is a thymidine analog that gets incorporated into DNA by cells undergoing replication, enabling DNA immunocapturing using BrdU antibodies ${ }^{20}$. This method has been successfully used in soils to probe active microbes ${ }^{21,22}$, however, this technique also suffers technical difficulties, such as a low labeling efficiency which typically require a the large amount of biological material to obtain sufficient amount of labeled DNA for sequencing ${ }^{15}$. Some newer approaches have coupled SIP to single cell analysis using Raman microspectroscopy or NanoSIMS to track metabolically active or newly formed cells ${ }^{23}$ by labeling them with $\mathrm{H}_{2}{ }^{18} \mathrm{O}^{24}$, but these methods currently have relatively low throughput and provide limited phylogenetic resolution.

Recently, bioorthogonal non-canonical amino acid tagging (BONCAT) was used to characterize active microbial aggregates from marine sediments ${ }^{25,26}$. This approach uses a relatively fast procedure and small amounts of material, attributes that make it appealing for probing soils. Communities are incubated with homopropargylglycine (HPG), a water soluble analog of methionine containing an alkyne group, which is incorporated into newly synthesized proteins ${ }^{27,28}$. Fluorescent dyes are then conjugated to HPG-containing proteins using an azide-alkyne "click chemistry" reaction ${ }^{27}$. As a consequence, cells that were translationally active during the incubation are fluorescently labeled and can be specifically recovered using fluorescenceactivated cell sorting (FACS) 26 . Compared to other methods of activity labeling, BONCAT is faster and less laborious, with the "click chemistry" reaction taking less than $2 \mathrm{~h}$. Perhaps more importantly, BONCAT labels newly made proteins and therefore does not rely on cell division and DNA synthesis to occur, facilitating short term incubations (minutes to hours) and interrogation of slowly dividing cells.

Here, we report the successful use of BONCAT to probe active members of the soil microbiome, as well as the integration of BONCAT with FACS cell sorting and sequencing of the active soil cells. For these studies we incubated soils from the Oak Ridge Field Research Site (ORFRS) site with HPG, and sorted labeled cells using FACS. The composition of the active community was determined through $16 \mathrm{~S}$ rRNA gene amplicon sequencing. The results were compared with the composition of the total soil community as well as to the $\sim 700$ isolates collected from the same field site. These analyses reveal that a large fraction of the active extractable microbes had close relatives among the local isolates collection and among major soil taxa identified in a recent global soil survey ${ }^{29}$.

\section{Results and discussion}

HPG is actively incorporated by cells in situ. We evaluated the utility of BONCAT for identifying translationally active cells from soil systems consisting of a highly heterogeneous matrix, and we coupled BONCAT with FACS to detect and recover individual active cells, as opposed to microbial aggregates consisting of hundreds of cells ${ }^{26}$. Soil samples were collected at the ORFRS in Oak Ridge, TN, USA and were horizontally cored at $30 \mathrm{~cm}$ and $76 \mathrm{~cm}$ below surface for the analyses of two distinct communities (Fig. 1a). The $30 \mathrm{~cm}$ soil had more quartz and less mica than the $76 \mathrm{~cm}$ sample that was composed of more clay (Supplementary Fig. 1). None of these samples had detectable amount of methionine based on LC-MS and therefore it is unlikely that there was significant competition from methionine for incorporation of HPG (Supplementary Fig. 2).

To confirm that HPG was actively incorporated by the cells in situ, we performed a killed control experiment on the $76 \mathrm{~cm}$ soil with duplicate samples for each treatment condition. Cells were either fixed before or after incubation with HPG by the addition of paraformaldehyde (3\% final concentration). Cells fixed prior to HPG incubation did not acquire fluorescence following the click reactions. Similarly, unfixed cells incubated without HPG also did not acquire fluorescence (See Fig. 1b for an example of how sort gates were determined). In contrast, both unfixed cells and cells fixed after HPG incubation acquired a distinct green fluorescence signal corresponding to the azide dye addition to the BONCAT labeled cells. The fraction of fluorescent cells and the per-cell fluorescence intensities were comparable between unfixed and post-incubation fixed cells, although the general shape of the analyzed events clouds differed in the cytograms (Supplementary Fig. 3, Supplementary table 2). This confirmed that HPG was only incorporated by active cells and that fixation was not required for the cycloaddition of the BONCAT azide fluorescent dye, as previously reported ${ }^{26,28}$. Therefore, all additional experiments were performed with unfixed cells to avoid the negative impacts of paraformaldehyde fixation on subsequent PCR amplification of 16S rRNA genes ${ }^{30}$.

Comparison of the extractable cells to the total soil community. Although the soil was directly transferred from the soil core and not agitated during the incubation, cells needed to be detached from the soil matrix following incubation with HPG and captured on a $0.2 \mu \mathrm{m}$ filter (see methods, Supplementary Table 3) for subsequent click reaction and FACS. We evaluated the impact on community composition introduced by this disaggregation step as it would filter out the extracellular $\mathrm{DNA}^{11}$ and cells passing through a $0.2 \mu \mathrm{m}$ filter. The disaggregation step could also impact community composition if some groups detach preferentially from the soil aggregates. Thus, we compared the $16 \mathrm{~S}$ rRNA composition of DNA extracted of bulk soil with the composition of detached cells captured on the $0.2 \mu \mathrm{m}$ filter.

The microbial community structure retrieved from the total soil DNA purification at $30 \mathrm{~cm}$ and at $76 \mathrm{~cm}$ differed at the phylum level (Fig. 2a and Supplementary Fig. 5). For example, the 
a

Incubation : $15^{\circ} \mathrm{C}-$ aerobic condition - dark
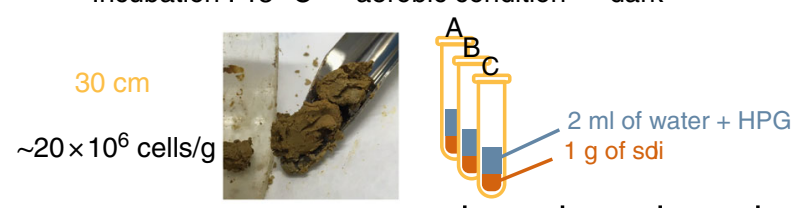

Sorted
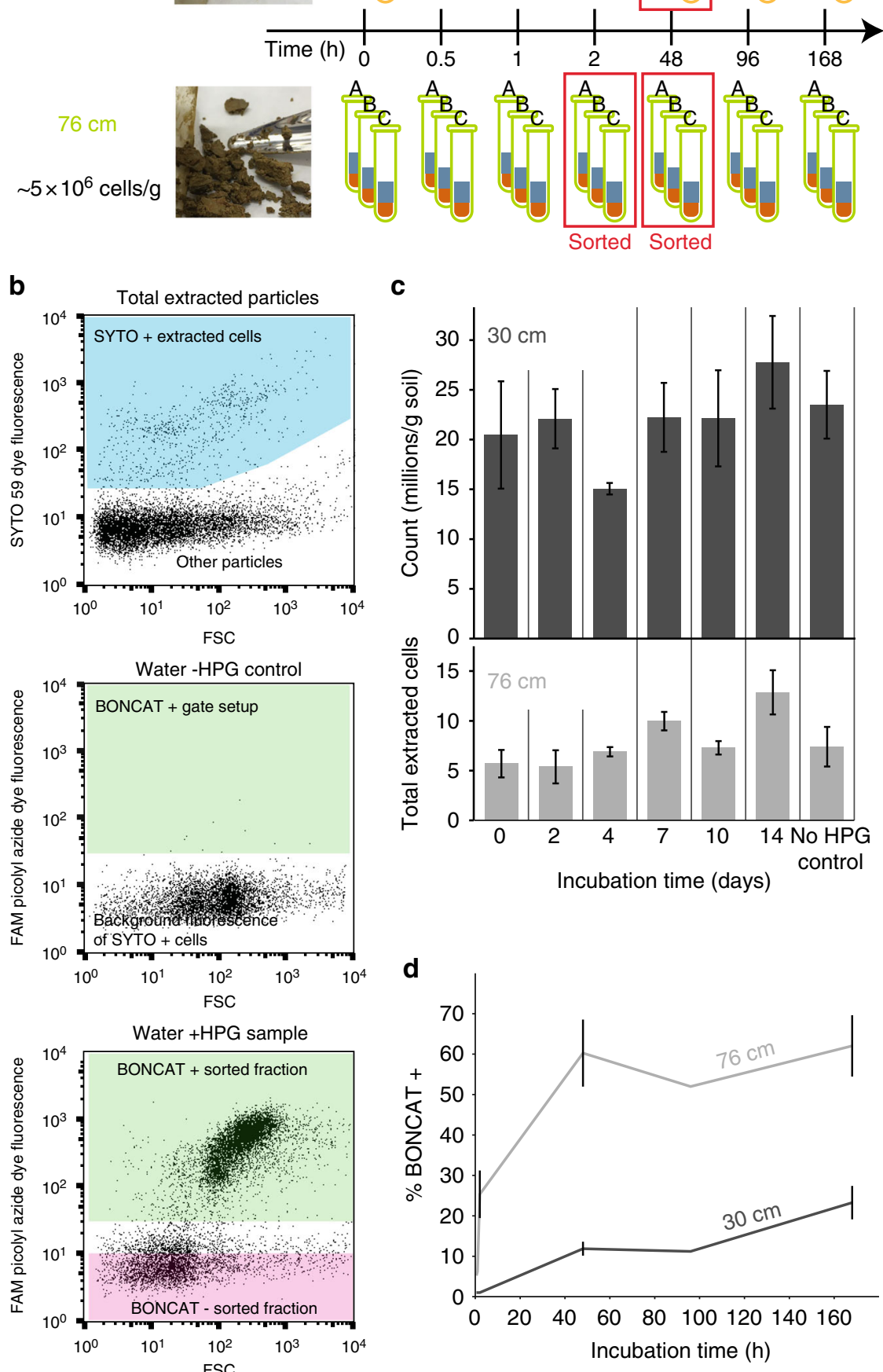

Fig. 1 Performing BONCAT-FACS on soil samples. a Details of the incubation conditions of the $76 \mathrm{~cm}$ and $30 \mathrm{~cm}$ soil samples. Samples were incubated in triplicate and three time points were sorted. $\mathbf{b}$ The gate drawing was done in two steps, first the cells were separated from the background particles based on their DNA dye staining SYTO59 fluorescence (Ex: $640 \mathrm{~nm} / \mathrm{Em}$ : [655-685 nm]), as pictured by the blue gate on the top panel. The SYTO+ cells were further analyzed for their BONCAT fluorescence with the FAM Picolyl dye (Ex: $488 \mathrm{~nm} / \mathrm{Em}: 530 \mathrm{~nm})$. The middle panel shows an example of a control sample that was water incubated and clicked (water -HPG control), the BONCAT gate (in green) was set such that less than $0.5 \%$ of events would fall in that gate (false positive). The bottom panel is an example of how the BONCAT+ and BONCAT - gates where set in a HPG incubated sample. Note that the green gate is the same than in the control sample. c Total extracted cell counts over time showing $\sim 20$ million cells per gram at $30 \mathrm{~cm}$ and $\sim 5$ million cells per gram at $76 \mathrm{~cm}$. d Temporal dynamics of BONCAT+ (express as a percent of the extractable cells) labeling for the $30 \mathrm{~cm}$ and the $76 \mathrm{~cm}$ sample. Error bars represent standard deviation $(n=3)$ 
a

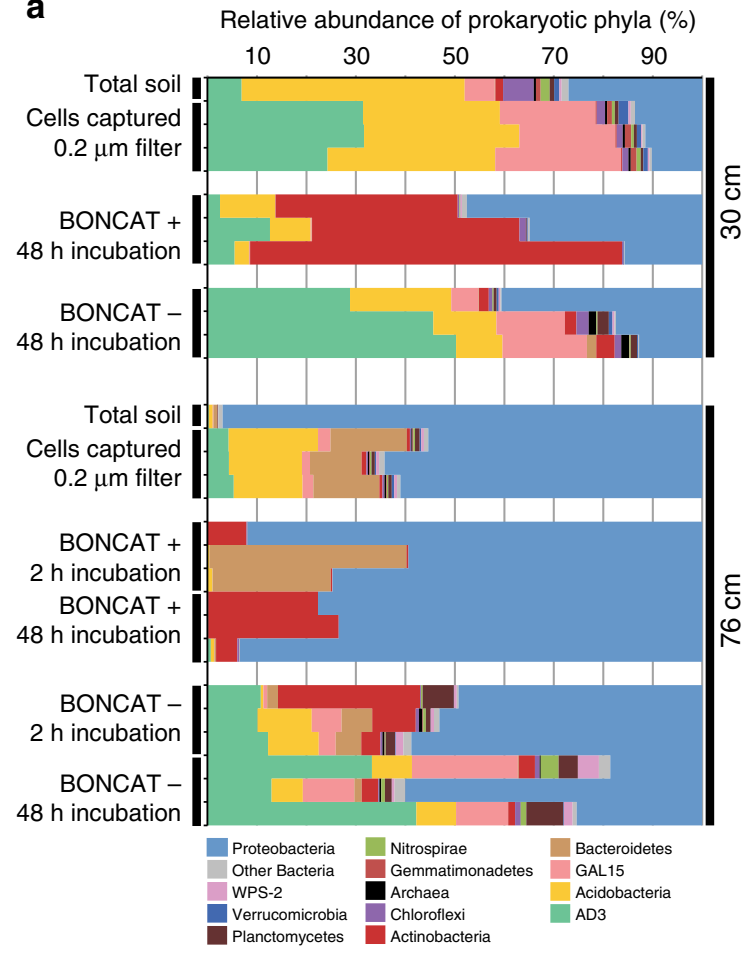

b
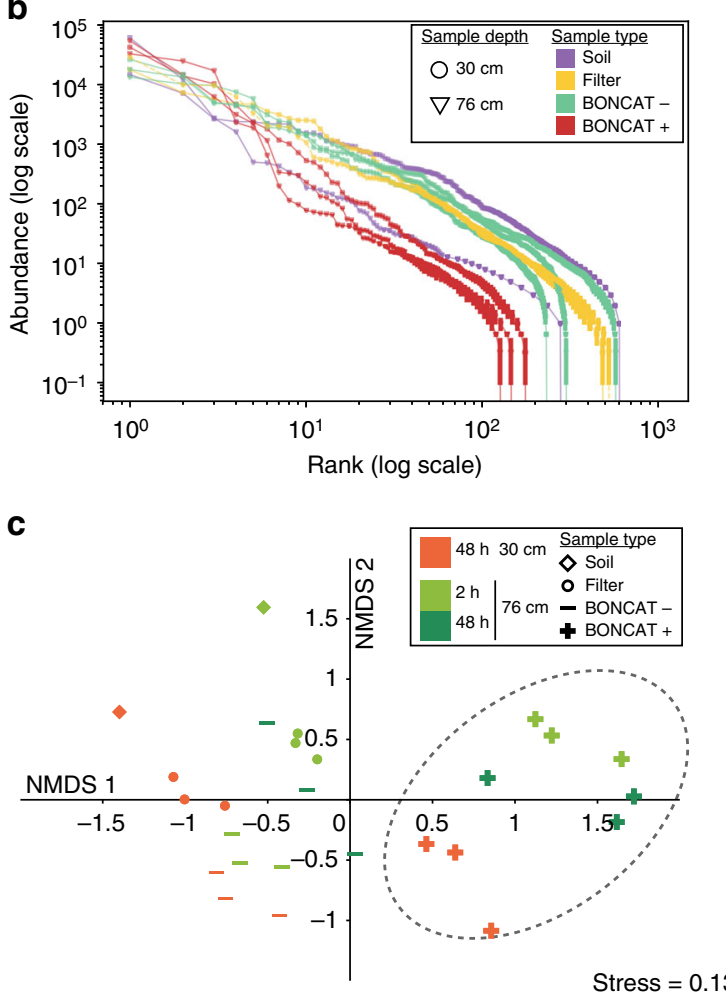

Fig. 2 Composition of total community and sorted fractions (16S rRNA gene sequencing). a Microbial diversity displayed at the phylum level for all samples analyzed. b Rank vs. abundance (absolute abundance from the rarefied OTU table at an even depth of 81000 sequences, see "methods") plot in log-log scale of the libraries of averaged biological replicates, standard deviations are displayed as error bars $(n=3)$. c NMDS ordination of the Bray Curtis pairwise distance of all libraries. 95\% confidence ellipse is displayed on the BONCAT+ group of samples. "Bulk Soil" samples are libraries constructed from total DNA extracted from soil, "Filter" samples are DNA extracted from all cells detached from soil and captured on a 0.2 $\mu \mathrm{m}$ filter, BONCAT+ and BONCAT - libraries were constructed from corresponding cell sorted samples

$30 \mathrm{~cm}$ soil was dominated by Acidobacteria as well as candidate phlya AD3 and GAL15. The $76 \mathrm{~cm}$ soil was largely dominated by Proteobacteria with a higher fraction of Bacteroidetes than found in the $30 \mathrm{~cm}$ soil. At the feature level (also called exact sequence variant (ESV), i.e., sequences denoised and clustered at $100 \%$ similarity), at both depths the most abundant feature was an Alphaproteobacterium genus Aquamicrobium that accounted for $8.77 \%$ and $72.9 \%$ of the analyzed sequences from $30 \mathrm{~cm}$ full soil and $76 \mathrm{~cm}$ full soil, respectively. This feature was only partially captured on the $0.2 \mu \mathrm{m}$ filters (it represented $2.4 \%$ and $3.1 \%$ respectively for the $76 \mathrm{~cm}$ and the $30 \mathrm{~cm}$ filters), which might be explained by (i) a technical bias in determining relative abundance $^{31}$ or (ii) non exclusively, the facts that this taxon exists largely as extracellular DNA in the soil, was not detached efficiently from the soil, or is of small size and not retained by the filter as suggested by the description of Aquamicrobium strains $^{32,33}$. The number of operational taxonomic units (OTUs; features clustered at $97 \%$ similarity) captured on the filters for the $30 \mathrm{~cm}$ sample was half the number retrieved from the total soil, whereas the number captured at $76 \mathrm{~cm}$ filters captured greater than or equal to the full soil sample in average (Supplementary Table 1). The OTUs that were present on the $76 \mathrm{~cm}$ filter sample and not retrieved in the soil were found in low abundance $(<0.1 \%)$ and might have come from the rare members of the soil microbiome. As expected the community composition of the extractable cell fraction captured on a filter was not identical to the bulk soil libraries. Since BONCAT labeling and cell sorting was performed on the total cells captured on a filter, referred to as the 'extractable fraction' throughout the remainder of the manuscript, results from sorted cells are compared to the extractable fraction unless otherwise noted. It is worth noting that the extractable fraction might also be a better proxy for the intact cellular fraction of the soil microbiome as it filters out extracellular DNA ${ }^{11}$ that can end up in sequencing results of DNA extracted from bulk soil.

Tracking of the active cell fraction through time using BONCAT. To identify individual active cells within soils, samples from $30 \mathrm{~cm}$ and $76 \mathrm{~cm}$ were incubated with HPG for up to one week $(168 \mathrm{~h})$ with periodic sampling followed by fluorescent labeling. The total number of cells was $\sim 20$ million cells $\mathrm{g}^{-1}$ soil at $30 \mathrm{~cm}$ and $\sim 5$ million cells $\mathrm{g}^{-1}$ soil at $76 \mathrm{~cm}$ (Fig. 1b). Cell population increased over time (Pearson $R=0.45, p=0.062$ and Pearson $R$ $=0.76, p<0.005$ at 30 and $76 \mathrm{~cm}$ respectively), indicating there was neither acute toxicity leading to massive cell loss nor a stimulation leading to a massive cell population bloom during the incubations. Although higher cell densities have been reported in other soils ${ }^{34}$, our soil samples were oligotrophic (Supplementary Fig. 1), with very low nitrogen $(<0.05 \%)$, no detectable amount of phosphorus, and a TOC $(<0.15 \%)$ of the same order of magnitude that bare arid land soils ${ }^{35}$. Moreover, we could only isolate 0.5-33 ng of DNA per $\mathrm{g}$ of soil while other soils often yield micrograms of DNA per gram of soil 34 . Altogether, these observations indicate that these soils might only be able to support a small population of cells, and we are therefore confident the extractable cell fraction in this study $\left(10^{6}-10^{7}\right.$ cells per gram of soil, Fig. 1c) represents a large fraction of the soil microbiome.

The fraction of BONCAT+ (Fig. 1b, d) cells increased over time in both soil samples (Fig. S4), with a distinct rate of labeling 
and fraction of labeled cells detected for both soil samples. For example, cells from the $76 \mathrm{~cm}$ soil were labeled quickly (clear BONCAT+ population were visible as early as $30 \mathrm{~min}$ incubation) and $\sim 60 \%$ of all extractable cells were labeled by $48 \mathrm{~h}$, whereas cells from the $30 \mathrm{~cm}$ soil were labeled more slowly (no BONCAT labeling after $1 \mathrm{~h}$ ) and only $\sim 20 \%$ total cells were labeled after $48 \mathrm{~h}$ (Fig. 1d and Supplementary Fig. 4). These differences, which were consistent among biological replicates, suggest that the microbial community found at $76 \mathrm{~cm}$ was composed primarily of active cells while the community at $30 \mathrm{~cm}$ had a larger fraction of inactive cells.

Previous studies found that only a small fraction of cells (as low as $0.1-2 \%$ ) were active at any giving time ${ }^{12}$, shaping the view that most soil microbes are dormant ${ }^{13,14}$. In this study, roughly $20 \%$ or more of the extractable cells we analyzed were active at both depths, and the $76 \mathrm{~cm}$ soil reached this value in only $30 \mathrm{~min}$ of incubation. The high number of active cells we found could be linked to the fact that we labeled translationally active cells while other techniques usually probe actively dividing cells therefore biasing against slow growers. The incubation conditions, which mimicked a natural event such as a heavy rain that saturates the soil, may have also impacted the fraction of active cells. Similar experiments involving other activity probing methods, with different incubation conditions and soil types will reveal the magnitude of variation that the active fraction undergoes under natural climatic conditions.

The active fraction is a selected subset of the total community. To determine the identity of extractable active cells, we sequenced the 16S rRNA genes of BONCAT+ cells from 30 and $76 \mathrm{~cm}$ soil samples. Specifically, triplicate collections of 35k-75k BONCAT+ cells recovered by FACS ( $2 \mathrm{~h}$ incubation of the $76 \mathrm{~cm}$ sample and $48 \mathrm{~h}$ incubations of the 76 and $30 \mathrm{~cm}$ samples) and characterized using iTag sequencing (Supplementary Table 1). Both soils were sequenced at the $48 \mathrm{~h}$ time point as it represents the beginning of the plateau phase of the BONCAT labeling for both cores (Fig. 1d). For the $76 \mathrm{~cm}$ soil, the $2 \mathrm{~h}$ time point was also sequenced to identify cells that were quickly labeled. Unlabeled cells (BONCAT-) were also sorted and sequenced from these time points (Fig. 1a). In order to compare the BONCAT sorted fractions to the total community at a large scale, we plotted the rank $v s$. abundance of all libraries (Fig. 2b). This plot clearly shows that the BONCAT+ populations were distinct from the rest of the samples, with a steeper slope reflecting a faster drop of diversity at higher ranks. The pattern for BONCAT - samples was similar to the extractable cells (filter samples). In order to assess if this difference was from compositional variation, we computed and ordinated a beta-diversity metric (Bray-Curtis measure of dissimilarity), and ordinated pairwise measures between samples (Fig. 2c). The resulting NMDS plot revealed that all the BONCAT+ fractions from both the 30 and the $76 \mathrm{~cm}$ formed a distinct group from the rest of the samples (Adonis, $F=2.65$, $p$ value $=0.001)$. This analysis supports the observation that the BONCAT - cells fraction resemble the total extractable cells, while the total DNA samples clustered further away. These results also indicate that the pools of BONCAT - cells, although of lower diversity compared to the control total soil and extractable cells, were a random subset of soil community, while the BONCAT+ fraction was clearly composed of a distinct and reproducible subset of the community.

Analyzing the phylogeny of the BONCAT + samples at the phylum level, we found that at $30 \mathrm{~cm}$, the extractable active fraction was dominated by Actinobacteria (Fig. 2a and Supplementary Fig. 5), with one Arthrobacter OTU encompassing 51\% of the retrieved sequences on average ("h" Fig. $3 a$ ), while the
$76 \mathrm{~cm}$ active population was dominated by Proteobacteria. At the OTU level (features clustered at $97 \%$ similarity) (Fig. 3), the BONCAT positives OTU h-e-f were highly active at both $30 \mathrm{~cm}$ and $76 \mathrm{~cm}$ independently of their abundance in the parent population. For instance, OTU h Arthrobacter was only recovered at low abundance (rank 214) from the extractable cells, while it is the most abundant OTU in the BONCAT+ fraction for this sample. In contrast, the most abundant members of the $76 \mathrm{~cm}$ community (e.g., OTU a Fig. 3) were BONCAT-, indicating that they did not respond to the incubation condition. These observations suggest that an OTU's activity could not be predicted from their abundance in the parent community alone.

Although we are confident that the BONCAT + fraction is composed of translationally active cells, the relative proportion of the OTUs within each library should be interpreted with some caution, as potential biases from PCR when producing the iTags libraries ${ }^{31,36}$ and sorting (in the detachment from the filter and DNA staining steps) may impact estimates of relative abundance. More precisely, a few OTUs account for the majority of the sequences retrieved in the BONCAT fractions while their abundance was lower in the total extractable community. Given that the size of the total extractable population only increased slightly during the first $48 \mathrm{~h}$ of incubation, this can be explained by two non-exclusive hypotheses: (i) some technical bias in determining relative abundance or (ii) real growth of certain OTUs balanced by loss of other members. While our experimental design does not allow us to distinguish between microbes that were already active and the ones that became active during the incubation, it seems reasonable to assume that the signal we measured is perhaps a mix of both types. Attempting a comparison of the $76 \mathrm{~cm}$ sample extractable BONCAT+ cells after 2 and $48 \mathrm{~h}$ of incubation we observe that the OTU $\mathrm{j}$ dropped while the OTU e and $\mathrm{h}$ increased in relative abundance (Fig. 3). We conclude that BONCAT is a promising method to interrogate through time community dynamic at the OTU level.

Another interesting finding from this study is that the BONCAT + signal plateaued at around $\sim 4$ million active cells per gram of soil independently of the size of the total population. The BONCAT + plateau may be due to the exhaustion of HPG by the cells or its sorption to the soil particles, or there may have been some resource limit within these samples that controlled the total number of active cells in each soil sample. It is also possible that some active cells were not labeled due to their inability to incorporate HPG. At this point, it is not possible to determine which scenario explains the observed plateau in our study, but the fact that BONCAT+ cells belonged to 251 different OTUs spanning 17 bacterial phyla and accounted for up to 70\% of the extractable cells, suggests, as previously noted $25,26,37$, that HPG is in fact incorporated by a large set of microbial species.

Comparison of BONCAT + cells with soil isolates and phylotypes. We examined how the composition of a culture collection generated from the same experimental site, (see "Methods" and Supplementary Data 1) compared to the diversity of the active, and presumably ecologically relevant, fraction of the community. More specifically, we compared $16 \mathrm{~S}$ rRNA gene sequences of BONCAT+ cells and total cells libraries (both total soil and extractable cells) to $16 \mathrm{~S}$ rRNA gene sequences from 687 isolates collected from this same location (Supplementary Data 1). Surprisingly, between 77 and $98 \%$ of total sequences from BONCAT + cells shared $>97 \%$ sequence similarity with the isolates. While the relative abundances should be interpreted with some caution due to potential impact of amplification or sorting bias ${ }^{31,38}$, these results suggest that a large fraction of the active extractable community had close cultured representatives. These findings 
a

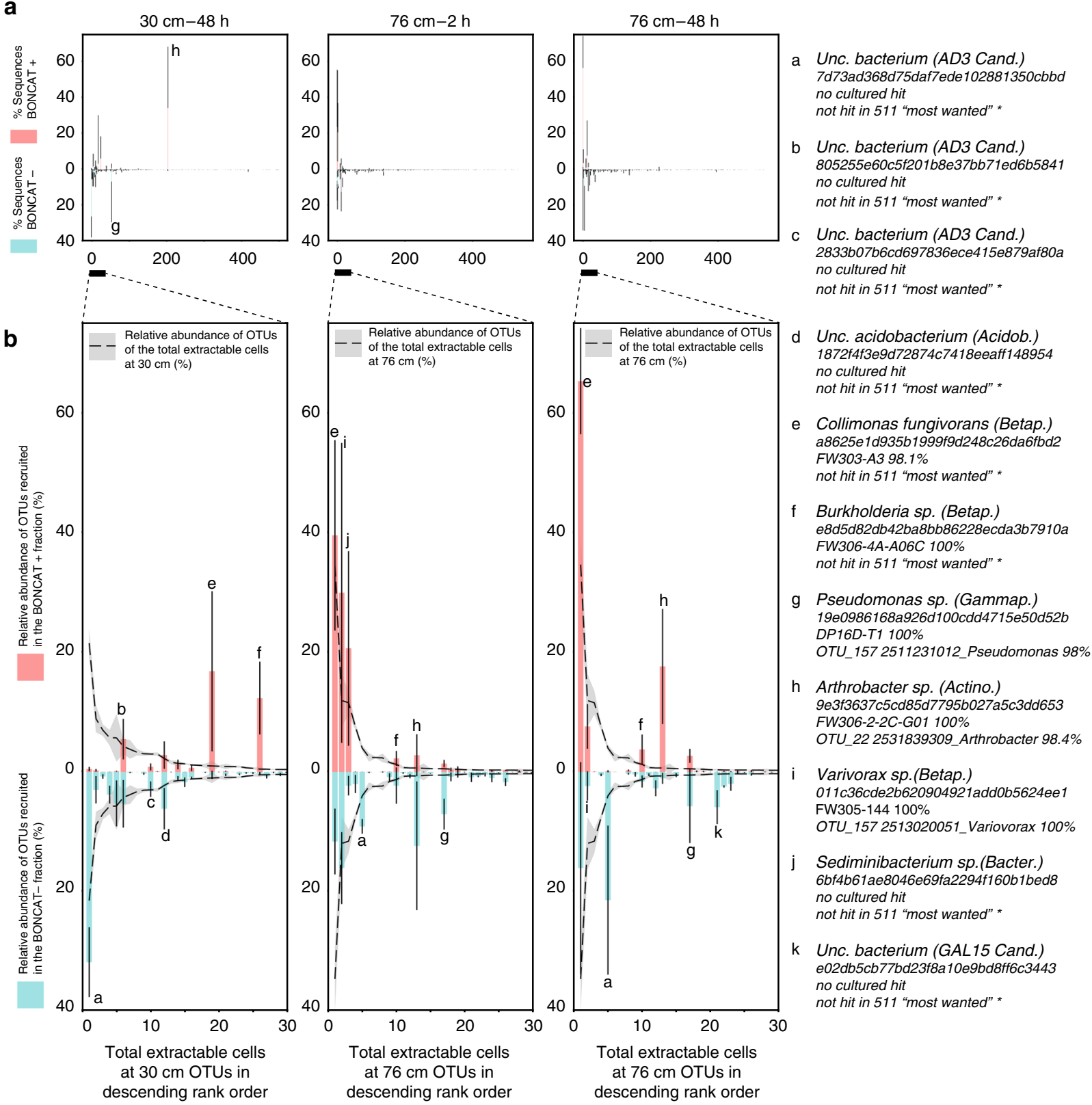

Fig. 3 Comparing the composition of the BONCAT+ and BONCAT- populations. a Relative abundance (in percent, \pm SD, $n=3$ ) of OTUs present in the BONCAT+ (red) and BONCAT - (blue) for the $30 \mathrm{~cm}-48 \mathrm{~h}$ incubation (left panel), $76 \mathrm{~cm}-2 \mathrm{~h}$ incubation (middle panel) and $76 \mathrm{~cm}-48 \mathrm{~h}$ incubation (right panel). The OTUs have been ranked in descending order from left to right according to their relative abundance on the filter samples (all cells detached and captured on a filter). b Close-up on the 30 most abundant OTUs overlaid with their abundance on the filter samples (dashed line, \pm SD shows as gray shading $n=3$ ). The most abundant OTUs are indexed from a to $k$. Their taxonomy, ID, hit in the ENIGMA culture collection and matches to the 511 most abundant soil microbiome ${ }^{29}$ is provided on the right legend panel. Error bars represent standard deviation $(n=3)$

also indicate the culture collection will be an important resource for exploring connections between soil communities and ecological processes at the Oak Ridge study site.

The observation that a substantial portion of the active extractable cells have cultured relatives aligns well with the recently published contribution from Delgado-Baquerizo et al..$^{29}$ that identified a list of 511 phylotypes (OTUs with 97\% cutoff) encompassing $44 \%$ of the microbial diversity of soils worldwide. Among these phylotypes, $45 \%$ had a cultured representative, suggesting that cultivation efforts have already yielded to isolate representatives of soil ubiquitous taxa. In order to further compare our dataset with these 511 ubiquitous soil phylotypes, we ran BLAST on a set of representative sequences of our libraries
OTUs and recovered the $>97 \%$ hits (Fig. $4 \mathrm{a}, \mathrm{b}$ ). We found that there was an overlap between the sequences found in our culture collection and from the 511 reference phylotypes ${ }^{29}$. Three of the most abundant BONCAT+ OTUs retrieved belonged to the 511 prominent members of the global atlas for soil microbiome ${ }^{29}$ (e.g., OTU g, h, i Fig. 3, 100\% sequence similarity), further supporting the idea that cultured isolates might be particularly relevant to the understanding of the soil microbiome in this study.

\section{Conclusions}

We find BONCAT to be a useful tool for the analysis of the active fraction of soil microbiomes when coupled to fluorescence 
a

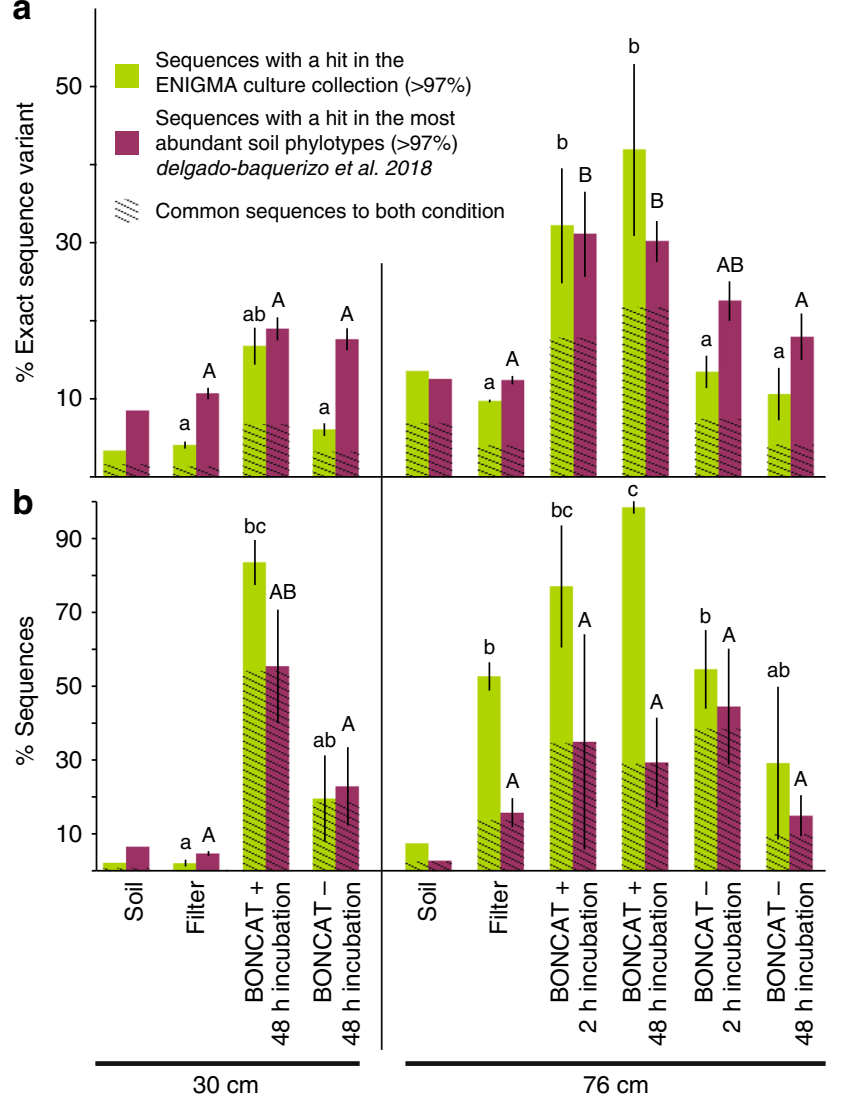

Fig. 4 Prevalence of soil isolates and ubiquitous soil OTUs among BONCAT + cells. a Percent features (non-clustered DADA2 results) and $\mathbf{b}$ percent sequences from the current libraries with a hit (>97\% sequence similarity) in the ENIGMA culture collection (this collection contains 697 full-length $16 \mathrm{~S}$ rRNA gene from strains that were isolated from the same field site as the samples considered in this study) (green), in the set of 511 phylotypes identified as the most abundant by ${ }^{29}$ (yellow) or both (dashed area). Data are average $(n=3) \pm S D$, letters indicate ANOVA post hoc significant differences. "soil" samples are libraries constructed from total DNA extracted from soil, "filter" samples are DNA extracted from all cells detached from soil and captured on a $0.2 \mu \mathrm{m}$ filter, BONCAT+ and BONCAT- libraries were constructed from corresponding cell sorted samples

activated single cell sorting and sequencing. This enables separating active cells from extracellular DNA, dormant microbes, and dead cells. BONCAT can be viewed as a filter that focuses environmental DNA analyses on the active and likely ecologically relevant extractable cell fraction. As with any filter, the BONCAT procedure may also introduce some biases, and it will need to be benchmarked against other activity probing strategies and tested in a larger variety of soil types. Nonetheless, we showed that BONCAT-FACS can be used to track the active cell population dynamics and dissect the behavior of active members at the phylum or OTU level. Our experiments resulted in consistent enrichment of a specific set of organisms in the BONCAT+ fraction, validating the reproducibility of BONCAT-FACS approach. Surprisingly, we found that a large fraction of the extractable cells was active under our incubation conditions (20-60\%) and that the sequences from the active population had close representatives in the culture collection established from the same sampling site. Although the biological finding of this study are limited to the specific soils and incubation conditions reported here our data demonstrate that BONCAT labeling can be applied to soil in a feasible, robust and reproducible manner, and could be widely used in future soil microbiome research.

\begin{abstract}
Methods
Description of the umbrella project of this study. This study and samples are part of the ENIGMA (Ecosystems Networks Integrated with Genes and Molecular Assemblies) project (http://enigma.lbl.gov/), a multi-PIs DOE SFA (Department of Energy Science Focus Area). The ENIGMA field site has already been studied ${ }^{39}$ and a culture collection of isolates from this exact field site was made available to this study, it is referred as the "the culture collection" in the main text (Supplementary File)
\end{abstract}

Samples collection and incubation condition. Two $4 \mathrm{~cm}$ diameter sample soil cores were collected horizontally from Oak Ridge, TN (GPS 35.941133, -84.336504 ) on 24 January 2017 from a silt loam area. A vertical trench was made and a first core was taken at $30 \mathrm{~cm}$ depth while the second one was collected at 76 $\mathrm{cm}$ depth. Both cores were shipped cooled and where stored in the dark at $4{ }^{\circ} \mathrm{C}$ until processing. At the time of the experiment (within 1-3 months after collection) a piece of $\sim 1 \mathrm{~g}$ of soil was sampled from the distal part of the core under sterile conditions for each replicate and placed into a $14 \mathrm{ml}$ polystyrene dual positions snap cap that was kept in the upper position allowing gas exchange through the incubation. Each replicate was incubated with $2 \mathrm{ml}$ of $50 \mu \mathrm{M} \mathrm{L}-$

homopropargylglycine (HPG, Click Chemistry Tools, Scottsdale, AZ, USA) in sterile water (DEPC diethyl pyrocarbonate treated filter sterilized water, $\mathrm{pH}$ 7) at $15^{\circ} \mathrm{C}$ in the dark, no mixing procedure was applied (i.e., we did not make a soil slurry) and the headspace was $12 \mathrm{ml}$. This temperature was chosen because it is the average surface temperature at the field site. The incubation was done aerobically because data from the field indicate the soil is aerobic above $1 \mathrm{~m}$ in this area $(\mathrm{T}$. Hazen, personal communication). Two milliliter was enough to fully submerge the $1 \mathrm{~g}$ of soil used for each replicate, this level of hydration ensured that all the soil pores were completely flooded and that there was no diffusion limitation of HPG. The addition of $2 \mathrm{ml}$ diluted the soil solutes and might represent a field event corresponding to a heavy rain capable of flooding the soil. Control samples were incubated under the same conditions with water but without HPG (water -HPG control). The full incubation design can be found in Fig. 1a. At the end of the incubation period (spanning $0.5-168 \mathrm{~h}$ ) $5 \mathrm{ml}$ of $0.02 \%$ Tween ${ }^{\circledR} 20$ (Sigma-Aldrich, ST Louis, MO, USA) in phosphate saline buffer (1X PBS) was added to each tube (already containing $2 \mathrm{ml}$ of HPG solution and $1 \mathrm{~g}$ of soil) and further vortexed at maximum speed for $5 \mathrm{~min}$ (Vortex-Genie 2, Scientific Industries, Inc., Bohemia, NY, USA) in order to detach cells from the soil particles. Culture tubes were then centrifuged at $500 \times g$ for 55 min (centrifuge 5810R, Eppendorf, Hamburg, Germany) and the supernatant containing the detached cells was aliquoted in $700 \mu \mathrm{l}$ aliquots and frozen right away at $-20^{\circ} \mathrm{C}$ in $10 \%$ glycerol (Sigma-Aldrich, ST Louis MO, USA) dissolved in PBS until further processing. The amount of supernatant collected per aliquot was chosen based on preliminary data that indicated that this amount was optimal to sort the target number of cells downstream.

Determining background fluorescent labeling in BONCAT. We performed a killed control experiments to validate the active incorporation of HPG and fluorescent labeling by cells by fixing duplicate soil samples from the $76 \mathrm{~cm}$ with $3 \%$ paraformaldehyde (PFA, Sigma-Aldrich, ST Louis MO, USA) for $1 \mathrm{~h}$ at RT. The aim of this experiment was to confirm that the cells needed to actively incorporate HPG to be labelled and that the simple diffusion of HPG into cells would not create artefactual signal ${ }^{25,26}$. Tests involving PFA were used as controls during methods development, and all sequencing results and were generated from unfixed sample.

We performed the PFA fixation (PFA, Sigma-Aldrich, ST Louis MO, USA) either prior incubation with HPG or right after. A set of samples was first fixed with $3 \%$ paraformaldehyde for $1 \mathrm{~h}$ at RT, while for another set PFA was spiked post incubation. The details of the incubation conditions can be found in Supplementary Table 2. These killed controls were compared to other live controls that were incubated without HPG in order to measure non-specific fluorescent labeling of cells. The killed controls and the no HPG controls went through the click chemistry reaction (see below) and their fluorescence in the BONCAT dye channel measured to determine the background fluorescence of the samples. Incubation times were $2 \mathrm{~h}$ and $48 \mathrm{~h}$. This set of sample was handled as previously described, cells were detached from the soil and frozen stock in $10 \%$ glycerol were kept at $-20^{\circ} \mathrm{C}$ until further evaluation of HPG incorporation, see below.

Soil properties, mineral and organic composition of the soils. Bulk X-ray powder diffraction was used to analyze the mineralogical composition of the soils cores. Powdered samples were loaded on an autosampler in a Rigaku SmartLab Xray diffractometer (Rigaku, The Woodlands, TX, USA), using a Bragg-Brentano geometry in a theta-theta configuration. Data were collected from $4^{\circ}$ to $70^{\circ}$ of $2 \theta$ using $\mathrm{Cu} \mathrm{Ka}$ radiation. After manual identification of the phases present, a Rietveld refinement was performed to obtain their weight fractions, using the software MAUD $^{40}$.

The soil chemistry analyses were performed by the UC Davis Analytical lab (https://anlab.ucdavis.edu/). Total carbon and total nitrogen were measure by the combustion method as described by the AOAC Official Method 272.43. The TOC 
was measured the same way after removal of carbonate via acid fumigation ${ }^{41}$. Soil nitrate and extractable ammonium where determined by the flow injection analyzer method ${ }^{42,43}$. The extractable phosphate (under detection limit of $1 \mathrm{ppm}$ for our samples) was measured by the Olsen-P method ${ }^{44}$, this method measures the bioavailable inorganic phosphate (orthophosphate).

Click reaction - BONCAT stain. A volume of $700 \mu$ of frozen cells of each sample were allowed to thaw at $4{ }^{\circ} \mathrm{C}$ for $\sim 1 \mathrm{~h}$. In the meantime, the click-reaction mixture was prepared by mixing the dye premix with the reaction buffer. This premix consisted of $5 \mu \mathrm{l}$ copper sulfate $\left(\mathrm{CuSO}_{4} 100 \mu \mathrm{M}\right.$ final concentration), of $10 \mu \mathrm{l}$ tris-hydroxypropyltriazolylmethylamine (THPTA, $500 \mu \mathrm{M}$ final concentration), and of $3.3 \mu \mathrm{l}$ (FAM picolyl azide dye, $5 \mu \mathrm{M}$ final concentration). The mix was incubated $3 \mathrm{~min}$ in the dark before being mixed with the reaction buffer, which was made of $50 \mu \mathrm{l}$ sodium ascorbate freshly prepared in $1 \mathrm{X}$ PBS at $5 \mathrm{mM}$ final concentration and $50 \mu \mathrm{l}$ of aminoguanidine $\mathrm{HCl}$ freshly prepared in 1X PBS at $5 \mathrm{mM}$ final concentration and $880 \mu \mathrm{l}$ of $1 \mathrm{X}$ PBS. All reagents were purchased from Click Chemistry Tools (Click Chemistry Tools, Scottsdale, AZ, USA). Once thawed, the cells were captured on a $0.2 \mu \mathrm{m}$ GTTP isopore ${ }^{\mathrm{m}} 25 \mathrm{~mm}$ diameter filter (MilliporeSigma, Burlington, MA, USA) and rinsed with $7 \mathrm{ml} \mathrm{1X} \mathrm{PBS.} \mathrm{The}$ filter was then placed on a glass slide and $80 \mu \mathrm{l}$ of the click reaction mixture was quickly added before covering the filter with a coverslip to avoid excess oxygen during the click reaction. The slides were incubated in the dark for $30 \mathrm{~min}$ and each filter was then thoroughly washed three times in a succession of three baths of $20 \mathrm{ml}$ 1X PBS for $5 \mathrm{~min}$ each. The filters were finally transferred to $5 \mathrm{ml}$ tubes (BD-Falcon $5 \mathrm{ml}$ round bottom tube with snap cap, Corning ${ }^{\mathrm{TM}}$, Corning, NY, USA) with $2 \mathrm{ml}$ of $0.02 \%$ Tween ${ }^{\circledR} 20$ in PBS, with the cells facing inwards and vortexed at maximum speed for $5 \mathrm{~min}$ to detach the cells. The tubes were incubated for $20 \mathrm{~min}$ at $25^{\circ} \mathrm{C}$, and subsequently stored at $4{ }^{\circ} \mathrm{C}$. Before being loaded onto the cell sorter (BD-Influx ${ }^{\mathrm{TM}}$, BD Biosciences, San Jose, CA, USA), the samples were filtered through a $35 \mu \mathrm{m}$ filter (BD-falcon $5 \mathrm{ml}$ tube with cell strainer cap, Corning ${ }^{\mathrm{TM}}$, Corning, NY, USA). Each set of experiment included water incubated samples (water-HPG control) that were clicked along with each set of samples, the fluorescence of the water incubated samples in the BONCAT dye channel was used to define the BONCAT staining background of each single click reaction.

Flow cytometer, cell count, and cell sorting. For the cell counts, the cells were prepared the exact same way as described above, but the click reaction was omitted and the cells detached from the soil were stained $1 X$ SYBR $^{\mathrm{TM}}$ (ThermoFisher Scientific, Invitrogen, Eugene OR, USA). For the evaluation of the BONCAT stained samples, cells were counterstained with the SYTO ${ }^{\mathrm{TM}} 59$ (ThermoFisher Scientific, Invitrogen, Eugene OR, USA) DNA dye for $5 \mathrm{~min}$ at RT at $0.5 \mu \mathrm{M}$. The cell sorter (BD-Influx ${ }^{\mathrm{TM}}$, BD Biosciences, San Jose, CA, USA) was setup to capture the FAM picolyl azide dye (excitation $=490 \mathrm{~nm} /$ emission $=510 \mathrm{~nm}$ ) in the green channel off a $488 \mathrm{~nm}$ blue laser and the counter DNA stain (excitation $=622 \mathrm{~nm}$, emission $=645 \mathrm{~nm}$ ) in the red channel off of a $630 \mathrm{~nm}$ red laser. A first gate was drawn on the SYTO positive (SYTO+) particles, under the assumption that this would capture the cells. SYTO+ events accounted for $0.1-5 \%$ of the events depending on the samples, most of the events being abiotic, most probably clays or other minerals (Supplementary Fig. 1). The BONCAT positive (BONCAT + ) and BONCAT negative (BONCAT-) where further gated as a sub-fraction of the SYTO + cells based on the BONCAT dye fluorescence. The no HPG control sample that went through click reaction steps along with the labeled samples was used to define the level of background BONCAT stain fluorescence, the BONCAT - gate was drawn under that line and BONCAT+ gate to ensure less than $0.5 \%$ false positives (Fig. 1b). The percent of BONCAT + determined for a time course for both the $30 \mathrm{~cm}$ and the $76 \mathrm{~cm}$ sample guided the sorting decisions. We decided to sort three biological replicates at two incubation time points for the $76 \mathrm{~cm}$ sample $(2 \mathrm{~h}$ and $48 \mathrm{~h}$ ) and three biological replicates at one time point for the $30 \mathrm{~cm}$ sample $(48 \mathrm{~h}$ ). A total of $35-75 \mathrm{k}$ cells (the target number was $75 \mathrm{k}$ but some samples had too low cell counts or too low labelled cell counts, see Supplementary table 1 for detailed counts) were sorted in parallel for the BONCAT+ and BONCAT - gates into a 96 well plate. Plates were frozen at $-80^{\circ} \mathrm{C}$ until processing.

Total DNA extraction from soil and filters. In order to compare sorted cells to the soil microbiome, total purified DNA was prepared from the soil cores and the extractable cells captured on a 0.2 GTTP isopore ${ }^{\mathrm{m}} 25 \mathrm{~mm}$ filter (MilliporeSigma, Burlington, MA, USA). We used the Qiagen-MoBio Power soil DNA kit (Qiagen, Hilden, Germany) following the manufacturer instructions, except for the lysis step that was performed by shaking the tubes at $30 \mathrm{~Hz}$ for $10 \mathrm{~min}$ in a tissue homogenizer (TissueLyser II, Qiagen, Hilden, Germany).

Libraries preparation and sequencing. In order to pellet the sorted cells, the 96 well plates were centrifuged at $7200 \times g$ for $60 \mathrm{~min}$ at $10^{\circ} \mathrm{C}$. The plates were further centrifuged upside-down for $20 \mathrm{~s}$ at $60 \times g$ to remove supernatant. The pelleted cells were lysed using PrepGEM (zyGEM, Charlottesville, VA, USA) chemical lysis in $2 \mu \mathrm{l}$ reactions following manufacturer's recommendation. $0.2 \mu \mathrm{l}$ of $10 \mathrm{X}$ Green buffer, $0.02 \mu \mathrm{l}$ of PrepGEM, $0.02 \mu \mathrm{l}$ of lysozyme and $1.8 \mu \mathrm{l}$ of water were added to each well. Note that six empty wells were submitted to PrepGEM lysis and library construction to account for potential contaminant. The plates were then placed in a thermocycler for $30 \mathrm{~min}$ at $37^{\circ} \mathrm{C}$ and $30 \mathrm{~min}$ at $75^{\circ} \mathrm{C}$. The iTag PCR was performed directly on the cell lysate following the JGI standard operating protocol (https://jgi.doe.gov/user-program-info/pmo-overview/protocols-samplepreparation-information/). Briefly, the V4 region of the 16S rRNA gene was amplified using the universal primer set 515F (GTGYCAGCMGCCGCGGTAA), 806R (GGACTACNVGGGTWTCTAAT) ${ }^{45}$. The adapter sequences, linkers and barcode were on the reverse primer. The 16S rRNA gene PCR was performed in a final volume of $25 \mu \mathrm{l}(10 \mu \mathrm{l}$ of the 5 Prime master mix, $0.5 \mu \mathrm{l}$ of the forward primer (at $10 \mu \mathrm{M}$ ), $1.5 \mu \mathrm{l}$ of the reverse primer (at $3.3 \mu \mathrm{M}$ ), $0.44 \mu \mathrm{l}$ of BSA, $10.5 \mu \mathrm{l}$ of water and $2 \mu \mathrm{l}$ of cell lysate). The PCR condition was as follows: after an initial denaturation step at $94^{\circ} \mathrm{C}$ for $3 \mathrm{~min}, 30 \mathrm{PCR}$ cycles occurred consisting on a $45 \mathrm{~s}$ denaturation step at $94^{\circ} \mathrm{C}$ followed by a 1 min annealing step at $50^{\circ} \mathrm{C}$ and a 1.5 min elongation step at $72^{\circ} \mathrm{C}$. A final elongation step of $10 \mathrm{~min}$ at $72^{\circ} \mathrm{C}$ was further added to finish all incomplete target sequences. The V4 region of the 16S rRNA gene from the total DNA extracted from the soil and from the cells enriched on filters were also amplified using the same PCR condition. The PCR products were cleaned using the Agencourt AMpure XP beads solution (Beckman Coulter Life Sciences, Indianapolis, IN, USA) to remove excess primers and primer dimers. PCR products were incubated with $80 \%(\mathrm{v} / \mathrm{v})$ beads for $5 \mathrm{~min}$ at $25^{\circ} \mathrm{C}$ before being placed on a magnetic holder (MagWell ${ }^{\mathrm{m}}$ Magnetic Separator 96, EdgeBio, San Jose, CA, USA). The supernatant was removed and the beads were washed with $70 \% \mathrm{v} / \mathrm{v}$ ethanol three times before being resuspended in $11 \mu \mathrm{l}$ of water. The total DNA extracts were processed in parallel, the only difference being that the iTag PCR was performed in $50 \mu \mathrm{l}$ final volume and the PCR product was resuspended in $16 \mu \mathrm{l}$ water after the bead clean-up step. PCR products were run on a High Sensitivity DNA assay Bioanalyzer chip (2100 Bioanalyser, Agilent, Santa Clara, CA, USA) to confirm fragment size and concentration. PCR products were pooled to an equimolar concentration and run on the Illumina MiSeq platform (Illumina, San Diego, CA, USA). Sequences data have been archived under the Bioproject ID PRJNA475109 at the NCBI.

Sequences processing. The sequences were processed using Qiime2 v2017.946. The sequences were imported in qiime2 using the fastq manifest format. Sequences were further denoised, the primer trimmed (20 nucleotides from each side) and paired using DADA2 ${ }^{47}$ as implemented in the Qiime dada2 denoisepaired plug-in. This step also included a chimera check using the consensus method. The output was a table of 4063 features (also called exact sequence variant (ESV)) of 6,419,059 sequences. 130 features had at least one hit in one of the six no template controls and were not considered for further analysis. The filtered table had 6,110,776 sequences gathered into 3933 features with a median value of 205,167 sequences per sample. The features were further clustered into operational taxonomic units (OTUs) at a threshold of $97 \%$ similarity using the vsearch cluster-features-de-novo plug-in. The clustered OTU table had 1533 OTUs in total. The absolute number of OTUs in 16S rRNA genes analyses can vary by up to three orders of magnitude depending on the technique used ${ }^{48}$, DADA2 is known to return a more conservative number than the previously widely used upfront clustering methods by decreasing the number of false positives ${ }^{47}$. This relatively low OTU count is also consistent with the very low level of organics (carbon and nitrogen) in these soils, which total organic carbon (TOC) are comparable to un-colonized arid lands where microbial diversity is known to be reduced ${ }^{49}$. The taxonomy of the representative sequences was assigned using the feature-classifier classify-sklearn plug-in (https://data.qiime2. org/2018.2/common/gg-13-8-99-515-806-nb-classifier.qza). This classifier was trained on the Greengenes database 13_8 99\% trimmed to the amplified region (V4 515F/806R). If the classifier could not assign the representative sequences at the phylum, then they were manually checked on the most up-to-date Silva SINA alignment service (https://www.arb-silva.de/aligner/) and the Silva classification was retained. The OTU table with assigned taxonomy was used to build the bar graph at the phylum level and all downstream analyses. Bray Curtis pairwise distance beta-diversity metric was computed on the OTU table and the obtained triangular distance matrix was ordinated using NMDS. The OTU table was further rarefied to an even sequence depth of 81,000 , the rarefied OTU table was used to construct the rank-abundance plot. OTUs in each library were sorted according to their abundance using the average method where a group of similar values gets the average rank value for the group; the abundance was plotted in log scale against the log rank value in descending order.

Comparison with reference dataset. We compared our iTag data with the 697 full-length 16S rRNA gene of the ENIGMA Project's existing culture collection from this field site and with the 511 16S rRNA gene sequences of the most abundant and widespread soil microbiome members, retrieved from DelgadoBaquerizo et al. ${ }^{29}$. We performed a nucleotide BLAST of one representative sequence per feature against the ENIGMA isolate database or the "511 most wanted soil phylotypes" 29 database using Geneious $\mathrm{R}^{\odot}$. A cutoff of $>97 \%$ similarity was used to determine if a sequence from our dataset had a match in 
the ENIGMA isolate database and/or the "511 most wanted soil phylotypes" database.

LC-MS soil metabolomics. Triplicates of $2 \mathrm{~g}$ of soils from $30 \mathrm{~cm}$ and $70 \mathrm{~cm}$ were extracted using $8 \mathrm{ml}$ of LCMS grade water and incubated $1 \mathrm{~h}$ on an overhead shaker at $4{ }^{\circ} \mathrm{C}$. Aqueous extractable components were collected by removal of insoluble material with centrifugation at $3220 \times g$ for $15 \mathrm{~min}$ at $4{ }^{\circ} \mathrm{C}$, filtration of supernatants through a $0.45 \mu \mathrm{m}$ PVDF syringe filter (MilliporeSigma, Burlington, MA, USA), followed by lyophilization of filtrates to remove water (Labconco 7670521, Kansas City, MO, USA). Dried samples were then resuspended in 500 $\mu$ of LCMS grade methanol, bath sonicated at $25^{\circ} \mathrm{C}$ for $15 \mathrm{~min}$, and then clarified by filtration through $0.2 \mu \mathrm{m}$ PVDF microcentrifugal filtration devices $\left(1000 \times g, 2 \mathrm{~min}, 25^{\circ} \mathrm{C}\right)$. Methanol extracts were spiked with an internal standard mix $\left({ }^{13} \mathrm{C},{ }^{15} \mathrm{~N}\right.$ universally labeled amino acids, 767964 , Sigma-Aldrich, USA, which included canonical amino acids, including methionine, at a final concentration of $10 \mu \mathrm{M}$ each). Metabolites in extracts were chromatographically separated using hydrophilic liquid interaction chromatography on a SeQuant 5 $\mu \mathrm{m}, 150 \times 2.1 \mathrm{~mm}, 200 \AA$ zic-HILIC column (1.50454.0001, Millipore) and detected with a Q Exactive Hybrid Quadrupole-Orbitrap Mass Spectrometer equipped with a HESI-II source probe (ThermoFisher Scientific). Chromatographic separations were done by an Agilent 1290 series HPLC system, used with a column temperature at $40^{\circ} \mathrm{C}$, sample storage was set at $4{ }^{\circ} \mathrm{C}$ and injection volume at $6 \mu$ l. A gradient of mobile phase A $(5 \mathrm{mM}$ ammonium acetate in water) and B ( $5 \mathrm{mM}$ ammonium acetate, $95 \% \mathrm{v} / \mathrm{v}$ acetonitrile in water) was used for metabolite retention and elution as follows: column equilibration at $0.45 \mathrm{~mL} 4$ $5 \mathrm{ml} \mathrm{min}{ }^{-1}$ in $100 \%$ B for $1.5 \mathrm{~min}$, followed by a linear gradient at $0.455 \mathrm{ml}$ $\min ^{-1}$ to $35 \% \mathrm{~A}$ over $13.5 \mathrm{~min}$, a linear gradient to $0.6 \mathrm{~mL} 5 \mathrm{ml} \mathrm{min}^{-1}$ and to

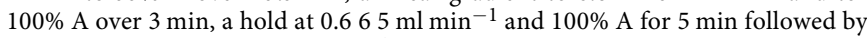
a linear gradient to $0.455 \mathrm{ml} \mathrm{min}^{-1}$ and $100 \% \mathrm{~B}$ over $2 \mathrm{~min}$ and re-equilibration for an additional $7 \mathrm{~min}$. Each sample was injected twice: once for analysis in positive ion mode and once for analysis in negative ion mode. The mass spectrometer source was set with a sheath gas flow of 55, aux gas flow of 20 and sweep gas flow of 2 (arbitrary units), spray voltage of $| \pm 3| \mathrm{kV}$, and capillary temperature of $400^{\circ} \mathrm{C}$. Ions were detected by the Q Exactive's data dependent MS2 Top2 method, with the two highest abundance precursory ions $(2.0 \mathrm{~m} / \mathrm{z}$ isolation window, 17,500 resolution, 1e5 AGC target, $2.0 \mathrm{~m} / z$ isolation window, stepped normalized collisions energies of 10,20 and $30 \mathrm{eV}$ ) selected from a full MS pre-scan $(70-1050 \mathrm{~m} / \mathrm{z}, 70,000$ resolution, 3e6 AGC target, $100 \mathrm{~ms}$ maximum ion transmission) with dd settings at 1e3 minimum AGC target, charges excluded above $|3|$ and a $10 \mathrm{~s}$ dynamic exclusion window. Internal and external standards were included for quality control purposes, with blank injections between every unique sample. QC mix was injected at the start and end of the injection sequence to ensure the stability of the signal through time and consisted of 30 compounds spanning a large range of $\mathrm{m} / z$, RT and detectable in both positive and negative mode. Extracted ion chromatograms for internal standard compounds were evaluated using MZmine version $2.26^{50}$ to ensure consistency between injections. Samples were analyzed using Metabolite Atlas ${ }^{50}$ (https://github.com/biorack/metatlas). Briefly, a retention time corrected compound library generated by linear regression comparison of QC standards against an in house retention time (RT)- $m / z$-MSMS library of reference compounds analyzed using the same LCMS methods was used for compound identification in samples where measured RT, $\mathrm{m} / \mathrm{z}$ and fragmentation spectra were compared with library predicted RT, theoretical $\mathrm{m} / \mathrm{z}$, library detected adducts and library MSMS fragmentation spectra. Compounds identification were retained when peak intensity was $>1 \mathrm{e} 4$, retention time difference from predicted was $<1 \mathrm{~min}, \mathrm{~m} / z$ was $<20 \mathrm{ppm}$ from theoretical, expected adduct was detected and at least one ion fragment matched the library spectra and were more abundant in at least one sample as compared to the average value $+1 \mathrm{SD}$ of the extraction controls. Only eight compounds met these criteria; average peak heights from the extracted ion chromatograms are reported in Fig. S5. The signal was overall very low owing to the low amount of organics in these soils. We checked for the presence of methionine manually using MZmine version $2.26^{32}$ and confirmed that there were no detectable amount of methionine in any of the sample analyzed. Metabolomics data has been deposited JGI genome portal \#1207416 along with the analysis file \#1207417.

Reporting summary. Further information on research design is available in the Nature Research Reporting Summary linked to this article.

\section{Data availability}

The 16S rRNA gene sequences from the libraries constructed for this study have been deposited to Genebank under the Bioproject ID PRJNA475109 [https://www.ncbi.nlm. nih.gov/bioproject/PRJNA475109]. The 16S rRNA genes from the ENIGMA culture collection are included in Supplementary Data 1. The raw flow cytometer data collected are displayed in Supplementary Figs. 4 and 5. The LCMS data and analysis are publicly available from the Joint Genome Institute Genome Portal: https://genome.jgi.doe.gov/ portal/201CAT_FD/201CAT_FD.info.html. The data file is \#1207416 and the analysis file is \#1207417. Source data for Figs. 1c, d, 2b, 3 and 4, and Supplementary Figs. 1b and $2 c$, are provided as a Source Data file.
Received: 25 September 2018 Accepted: 7 May 2019

Published online: 24 June 2019

\section{References}

1. Bardgett, R. D. \& Van Der Putten, W. H. Belowground biodiversity and ecosystem functioning. Nature 515, 505-511 (2014).

2. Torsvik, V. \& Øvreås, Å. Microbial diversity and function in soil: from genes to ecosystems. Curr. Op. Microbiol 5, 240-245 (2002).

3. Fierer, N. Embracing the unknown: disentangling the complexities of the soil microbiome. Nat. Rev. Microbiol. 15, 579-590 (2017).

4. Schloss, P. D. \& Handelsman, J. Toward a census of bacteria in soil. PLoS Comput. Biol. 2, e92 (2006).

5. Fierer, N., Bradford, M. A. \& Jackson, R. B. Toward an ecological classification of soil bacteria. Ecology 88, 1354-1364 (2007).

6. Ramirez, K. S. et al. Detecting macroecological patterns in bacterial communities across independent studies of global soils. Nat. Microbiol 3, 1-8 (2017).

7. Fierer, N. \& Jackson, R. The diversity and biogeography of soil bacterial communities. Proc. Natl Acad. Sci. USA 103, 626-631 (2006).

8. Crowther, T. W. et al. Predicting the responsiveness of soil biodiversity to deforestation: a cross-biome study. Glob. Chang. Biol. 20, 2983-2994 (2014).

9. Serna-Chavez, H. M., Fierer, N. \& Van Bodegom, P. M. Global drivers and patterns of microbial abundance in soil. Glob. Ecol. Biogeogr. 22, 1162-1172 (2013).

10. Barberán, A., Bates, S. T., Casamayor, E. O. \& Fierer, N. Using network analysis to explore co-occurrence patterns in soil microbial communities. ISME J. 6, 343-351 (2012).

11. Carini, P. et al. Relic DNA is abundant in soil and obscures estimates of soil microbial diversity. Nat. Microbiol 2, 1-6 (2016).

12. Blagodatskaya, E. \& Kuzyakov, Y. Active microorganisms in soil: Critical review of estimation criteria and approaches. Soil Biol. Biochem. 67, 192-211 (2013).

13. Jones, S. E. \& Lennon, J. T. Dormancy contributes to the maintenance of microbial diversity. Proc. Natl Acad. Sci. USA 107, 5881-5886 (2010).

14. Lennon, J. T. \& Jones, S. E. Microbial seed banks: the ecological and evolutionary implications of dormancy. Nat. Publ. Gr. 9, 119-130 (2011).

15. Singer, E., Wagner, M. \& Woyke, T. Capturing the genetic makeup of the active microbiome in situ. ISME J. 11, 1949-1963 (2017).

16. Pett-Ridge, J. \& Firestone, M. K. Using stable isotopes to explore rootmicrobe-mineral interactions in soil. Rhizosphere 3, 244-253 (2017).

17. Verastegui, Y., Cheng, J. \& Engel, K. Multisubstrate isotope labeling and metagenomic analysis of active soil bacterial communities. MBio 5, 1-12 (2014).

18. Neufeld, J. D. et al. DNA stable-isotope probing. Nat. Protoc. 2, 860-866 (2007).

19. Jameson, E. et al. In Metagenomics: Methods and Protocols (eds Streit, W. R. \& Daniel, R.) 57-74, https://doi.org/10.1007/978-1-4939-6691-2_5 (Springer New York, 2017).

20. Artursson, V. \& Jansson, J. K. Use of Bromodeoxyuridine immunocapture to identify active bacteria associated with Arbuscular Mycorrhizal Hyphae. Society 69, 6208-6215 (2003).

21. David, M. M. et al. Microbial ecology of chlorinated solvent biodegradation. Environ. Microbiol. 17, 4835-4850 (2015).

22. Bravo, D. et al. Identification of active oxalotrophic bacteria by Bromodeoxyuridine DNA labeling in a microcosm soil experiments. FEMS Microbiol. Lett. 348, 103-111 (2013).

23. Eichorst, S. A. et al. Advancements in the application of NanoSIMS and Raman microspectroscopy to investigate the activity of microbial cells in soils. FEMS Microbiol. Ecol. 91, 1-14 (2015).

24. Berry, D. et al. Tracking heavy water $\left(\mathrm{D}_{2} \mathrm{O}\right)$ incorporation for identifying and sorting active microbial cells. Proc. Natl Acad. Sci. USA 112, E194-E203 (2015).

25. Hatzenpichler, R. et al. In situ visualization of newly synthesized proteins in environmental microbes using amino acid tagging and click chemistry. Environ. Microbiol. 16, 2568-2590 (2014).

26. Hatzenpichler, R. et al. Visualizing in situ translational activity for identifying and sorting slow-growing archaeal-bacterial consortia. Proc. Natl Acad. Sci. USA 113, E4069-E4078 (2016).

27. Dieterich, D. C., Link, A. J., Graumann, J., Tirrell, D. A. \& Schuman, E. M. Selective identification of newly synthesized proteins in mammalian cells using bioorthogonal noncanonical amino acid tagging (BONCAT). Proc. Natl Acad. Sci. USA 103, 9482-9487 (2006).

28. Hatzenpichler, R. \& Orphan, V. J. In Hydrocarbon and Lipid Microbiology Protocols - Springer Protocols Handbooks 1-29, https://doi.org/10.1007/8623 (2015). 
29. Delgado-baquerizo, M. et al. A global atlas of the dominant bacteria in soil. Science 325, 320-325 (2018).

30. De Giorgi, C., Finetti Sialer, M. \& Lamberti, F. Formalin-induced infidelity in PCR-amplified DNA fragments. Mol. Cell. Probes 8, 459-462 (1994).

31. Hansen, M. C., Tolker-Nielsen, T., Givskov, M. \& Molin, S. Biased 16S rDNA PCR amplification caused by interference from DNA flanking the template region. FEMS Microbiol. Ecol. 26, 141-149 (1998).

32. Bambauer, A., Rainey, F. A., Stackebrandt, E. \& Winter, J. Characterization of Aquamicrobium defluvii gen. nov. sp. nov., a thiophene-2-carboxylatemetabolizing bacterium from activated sludge. Arch. Microbiol. 169, 293-302 (1998).

33. Kampfer, P., Martin, E., Lodders, N. \& Jackel, U. Transfer of Defluvibacter lusatiensis to the genus Aquamicrobium as Aquamicrobium lusatiense comb. nov. and description of Aquamicrobium. Int. J. Syst. Evol. Microbiol. 59, 2468-2470 (2019).

34. Miller, D. N., Bryant, J. E., Madsen, E. L. \& Al, M. E. T. Evaluation and optimization of DNA extraction and purification procedures for soil and sediment samples. Appl. Environ. Microbiol. 65, 4715-4724 (1999).

35. Beraldi-Campesi, H., Hartnett, H. E., Anbar, A., Gordon, G. W. \& GarciaPichel, F. Effect of biological soil crusts on soil elemental concentrations: implications for biogeochemistry and as traceable biosignatures of ancient life on land. Geobiology 7, 348-359 (2009).

36. Martin-Laurent, F. et al. DNA extraction from soils: old bias for new microbial diversity analysis methods DNA extraction from soils: old bias for new microbial diversity analysis methods. Appl. Environ. Microbiol. 67, 2354-2359 (2001).

37. Leizeaga, A., Estrany, M., Forn, I. \& Sebastián, M. Using click-chemistry for visualizing in situ changes of translational activity in Planktonic marine bacteria. Front. Microbiol 8, 1-11 (2017).

38. Martin-Laurent, F. et al. DNA extraction from soils: old bias for new microbial diversity analysis methods. Appl. Environ. Microbiol. 67, 2354-2359 (2001).

39. Smith, M. B. et al. Natural bacterial communities serve as quantitative geochemical. MBio 6, 1-13 (2015).

40. Lutterotti, L., Matthies, S. \& Wenk, H. MAUD: a friendly Java program for material analysis using diffraction. CPD Newsl. 21, 14-15 (1999).

41. Harris, D., Horwa, W. R. \& Kessel, CVan . Acid fumigation of soils to remove carbonates prior to toal organic carbon or carbon-13 isotopic analysis. Soil Sci. Soc. Am. J. 1856, 1853-1856 (2001).

42. Hofer, S. Determination of ammonia (salicylate) in $2 \mathrm{M} \mathrm{KCl}$ soil extracts by flow injection analysis. QuikChem Method 12-107-06- (2003).

43. Knepel, K. Determination of nitrate in $2 \mathrm{M} \mathrm{KCl}$ soil extracts by flow injection analysis. QuikChem Method 12-107-04-1-B (2003).

44. Olsen, S. R. \& Sommers, L. E. In Methods of soil analysis: Part 2. Chemical and microbiological properties. Agron. Mongr. 9. 2nd edn. 403-430 (ASA and SSSA, Madison, WI, 1982).

45. Walters, W. A. et al. PrimerProspector: de novo design and taxonomic analysis of barcoded polymerase chain reaction primers. Bioinformatics 27 , 1159-1161 (2011).

46. Bolyen, E. et al. QIIME 2: Reproducible, interactive, scalable, and extensible microbiome data science. PeerJ Preprints 6, e27295v2 (2018).

47. Callahan, B. J. et al. DADA2: High resolution sample inference from amplicon data. bioRxiv 13, 0-14 (2015).

48. Flynn, J. M., Brown, E. A., Chain, F. J. J., MacIsaac, H. J. \& Cristescu, M. E. Toward accurate molecular identification of species in complex environmental samples: testing the performance of sequence filtering and clustering methods. Ecol. Evol. 5, 2252-2266 (2015).
49. Bowker, Ma, Maestre, F. T. \& Escolar, C. Biological crusts as a model system for examining the biodiversity-ecosystem function relationship in soils. Soil Biol. Biochem. 42, 405-417 (2010).

50. Yao, Y. et al. Analysis of metabolomics datasets with high-performance computing and metabolite atlases. Metabolites 5, 431-442 (2015).

\section{Acknowledgements}

The authors would like to acknowledge Dominique Joyner for the samples collection and shipping, Marco Voltolini (LBNL) for his support in the X-Ray diffraction analyses, Michael Thorgersen (LBNL) and Mike W. Adams (LBNL) for sharing the 16S rRNA gene sequence of the isolate MT58RC and the JGI sequencing group for its technical assistance. This work was funded by a discovery proposal awarded to T. Northen as part of the ENIGMA Science Focus Area funded by the Genomic Sciences Program, Office of Biological and Environmental Research, Department of Energy Office of Science. The work conducted by the U.S. Department of Energy Joint Genome Institute, a DOE Office of Science User Facility, is supported by the Office of Science of the U.S. Department of Energy under Contract No. DE-AC02-05CH11231.

\section{Author contributions}

E.C., R.R.M., and T.R.N. designed the experiment, acquired and analyzed data and wrote the manuscript. J.S. designed the experiment, acquired and analyzed data. D.G. designed the experiment and operated the FACS. N.N. prepared libraries for sequencing. T.C.H. provided samples. B.P.B. supported data analysis. R.C. shared data from the ENIGMA culture collection. All authors provided feedback on the manuscript.

\section{Additional information}

Supplementary Information accompanies this paper at https://doi.org/10.1038/s41467019-10542-0.

Competing interests: The authors declare no competing interests.

Reprints and permission information is available online at http://npg.nature.com/ reprintsandpermissions/

Peer review information: Nature Communications thanks the anonymous reviewer(s) for their contribution to the peer review of this work.

Publisher's note: Springer Nature remains neutral with regard to jurisdictional claims in published maps and institutional affiliations.

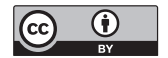

Open Access This article is licensed under a Creative Commons Attribution 4.0 International License, which permits use, sharing, adaptation, distribution and reproduction in any medium or format, as long as you give appropriate credit to the original author(s) and the source, provide a link to the Creative Commons license, and indicate if changes were made. The images or other third party material in this article are included in the article's Creative Commons license, unless indicated otherwise in a credit line to the material. If material is not included in the article's Creative Commons license and your intended use is not permitted by statutory regulation or exceeds the permitted use, you will need to obtain permission directly from the copyright holder. To view a copy of this license, visit http://creativecommons.org/ licenses/by/4.0/.

This is a U.S. government work and not under copyright protection in the U.S.; foreign copyright protection may apply 2019 